\title{
Theoretical research of stability of movement of the combined fertilizing-and-sowing machine-tractor aggregate
}

\author{
V. Bulgakov, \\ Dr. Sc., academician of NAAS, \\ National University of Bioresources and nature use of Ukraine \\ V. Adamchuk, \\ Dr. Sc., academician of NAAS, \\ National Science Center "Institute of Mechanization and Electrification Agriculture" \\ Ye. Petrychenko, \\ National Science Center "Institute of Mechanization and Electrification Agriculture" \\ V. Nadykto, \\ Corresponding Member of NAAS, Doctor of Engineering \\ Tauria state agrotechnological university \\ V. Kuvachov, \\ Assoc. Prof. Eng., PhD. \\ Tavria State Agrotechnological University
}

The purpose. To increase efficiency of operation of fertilizing- and-sowing aggregate in surging plane by justification of its scheme and design parameters. Methods. Basic positions of theoretical mechanics, statistical dynamics, the theory of autocontrol of linear dynamic systems and theory of a tractor, creation of programs for calculation on the PC. Results. New mathematical models of operation of the combined fertilizing-and-sowing machine-tractor aggregate in surging plane are developed. Their application allows justifying constructive and kinematic parameters of the aggregate. Conclusions. For security of the best controllability of driving the combined fertilizing-and-sowing aggregate the preference should be given to great values of distance from points of the trailer of fertilizer sower and grain drill to the centers of their masses and length of short tongue of fertilizer sower and grain drill. Thus boundary of increase of length of short tongue of fertilizer sower is such which predetermines trouble-free maneuverability of the combined aggregate.

Key words: combined aggregate, fertilizing-and-sowing unit, differential equations, programs for PC.

Actuality of the question. The problem of increasing the effectiveness of using the main dose of mineral fertilizers during the sowing of cereals and other crops has now remained one of the most urgent [1]. Numerous previous studies have established that the application of mineral fertilizers together with sowing of corn and other crops when starting dose of fertilizer made at the level of the bed of seed and basic dose of fertilizers introduced below the seeding offset horizontally, can achieve savings of fertilizer by $30-45 \%[1,2]$.

Thus, it is obvious that combining the sowing of cereals and other crops with the main fertilizer of the soil is a resource-saving measure. In this regard, there is a need to develop and study of the combined machine and tractor units that would allows for simultaneous sowing fertilizer and immediately starting major doses. Moreover, its constructive and technological implementation should ensure an increase in technical and economic performance. The practical solution to this task is due to the relevance of this work.

Analysis of recent research and publications. Important scientific and practical tasks of planting and fertilizing crops could solve the development and application of the combined machine and tractor units that are built in a modular fashion and provide significant advantages for their use in a production environment [37]. Decisive contribution to the theory and practice of the issue made Vasilenko P.M., Pogorily L.V., Adamchuk V.V., Bulgakov V.M., Yevtenko V.G., Kravchuk V.I., Nedovyesov V.I., Lebedev A.T., Paschenko 
V.F., Samorodov V.B., Nadykto V.T., Kyrchev V.M., Kuvachov V.P., Wong J.Y., Tullberg J.N., Williford J.R. etc. scientists

At the same time, their theoretical dependences developed and the obtained practical results can not be used to substantiate the structural and technological parameters of the combined fertilizer-seeding machinetractor unit. First of all, because its constructive execution was not considered in the studies and there was no place in the operation of the equipment. Second, the scientists analyzed the dynamics of plane-parallel movement trailed, mounted and self-propelled machine and tractor units does not include the specific block zadnoprychipnyh machinery and equipment, and therefore can not be used to solve this problem. As a result, this does not allow to achieve a significant improvement in the technical and economic performance of the fertilizer and seed aggregate. But it noted [7] that the main movement of agricultural machines is their plane-parallel movement, since this kind of movement determines agronomic and operational and technical performance and productivity. The search for a scientifically grounded decision aimed at eliminating these shortcomings, and formed the basis of this study.

The purpose. Improvement of the efficiency of the fertilizer-sowing unit in the longitudinal-horizontal plane by substantiating its scheme and structural and technological parameters.

Methods. The basic provisions of theoretical mechanics, statistical dynamics, theory of automatic regulation of linear dynamical systems and tractor theory, programming and calculations on PC are used.

Research results. In the decision of the set tasks of researches the scheme of the combined machinetractor unit for the intra-soil complex mineral fertilization of a ground with simultaneous sowing of various grain crops is developed (fig. 1).

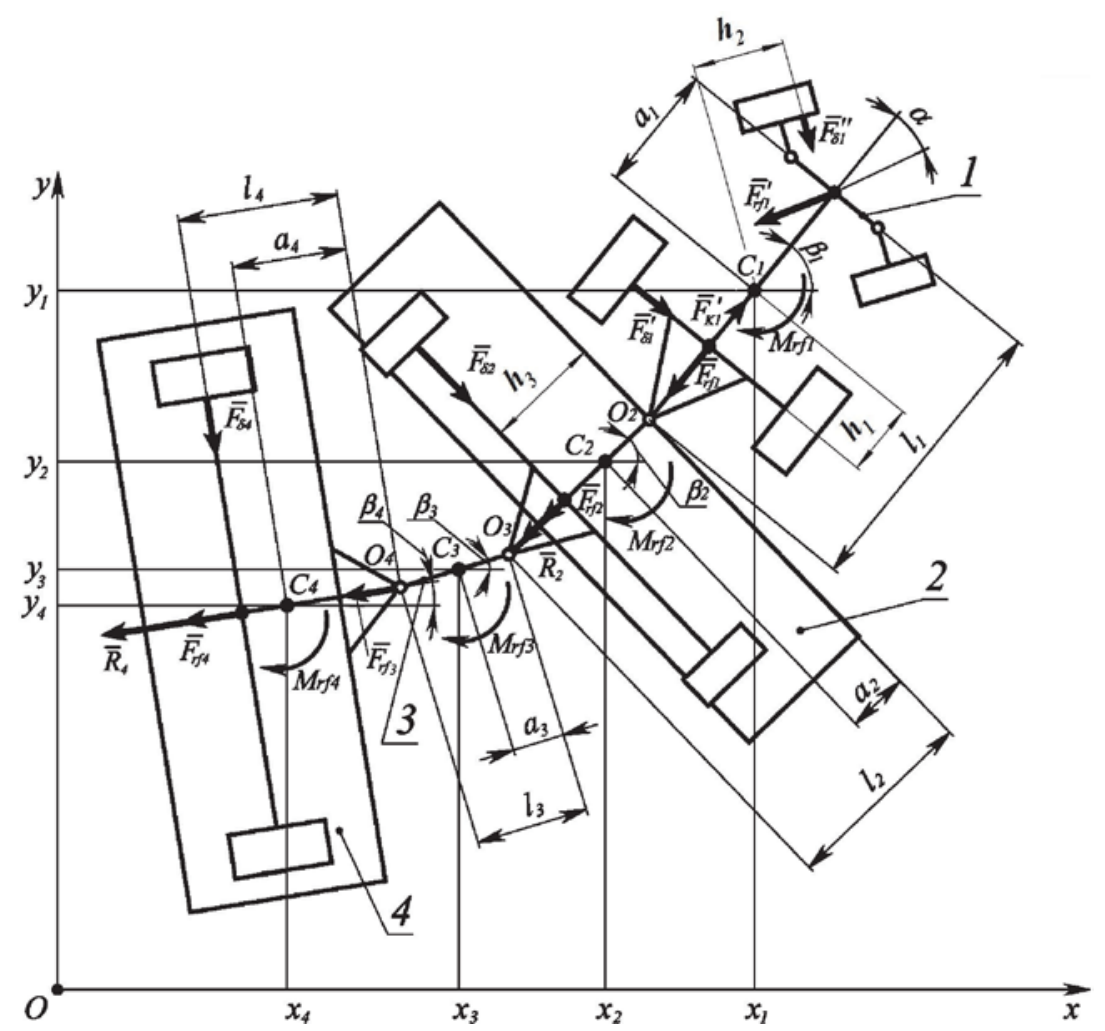

Fig. 1 - Equivalent scheme of combined fertilizer-seeding machine-tractor unit: 1 - tractor; 2 - fertilizer aggregate; 3 - trailer coupling; 4 - seeding unit

The equivalent scheme (fig. 1) of a fertilizer-seeding machine-tractor unit, as a dynamic system, has six degrees of freedom, therefore, and the differential equations of motion of a dynamic system will be described by six independent generalized coordinates: $x_{1}, y_{1}, \beta_{1}, \beta_{2}, \beta_{3}, \beta_{4}$ where $x_{1}, y_{1}$-coordinates of the center of mass of the aggregating tractor; $\beta_{1}, \beta_{2}, \beta_{3}, \beta_{4}$ - respectively, the angles formed by 
the longitudinal axes of the links of the mechanical system with the axis $O x ; \quad m_{i}(i=\overline{1,4})$ - masses of parts of the mechanical system; $C_{i}\left(x_{i}, y_{i}\right)$ - center of masses of the i-th link system $(i=1, \overrightarrow{4}) ; a_{i}$ distance from the center of the masses to its front hinge; $l_{i}$ - distance between two adjacent axes of joints.

To establish the interdependence of the structural and technological parameters of the combined fertilizer-seeding unit with its stability of motion, one can use the initial equations in the form of the Lagrange of the second kind of the following type:

$$
\frac{d}{d t}\left(\frac{\partial T}{\partial q_{s}}\right)-\frac{\partial T}{\partial q_{s}}=Q_{s} \quad(s=\underline{1,6}),
$$

where $T$ - the kinetic energy of the mechanical system;

$q_{s}$ - generalized coordinate;

$S$ - number of generalized coordinates;

$Q_{s}$ - a generalized force corresponding to a generalized coordinate.

After determining for each link of kinetic energy, its partial derivatives with the corresponding generalized coordinates and generalized forces, we have a system of differential equations that describes the movement of the combined fertilizer-seeding unit in a horizontal plane:

$$
\begin{aligned}
& \left(F_{\delta 1}^{\prime}-F_{\delta 2}\right) \beta_{1}-F_{\delta 2} \beta_{2}-F_{\delta 4} \beta_{4}= \\
& =F_{k 1}-F_{r f 1}^{\prime}-F_{\delta 2} \alpha-F_{r f 1}-F_{r f 2}-R_{2}-F_{r f 3}-F_{r f 4}-R_{4} \text {; } \\
& \left(m_{1}+m_{2}+m_{3}+m_{4}\right) \ddot{y}_{1}-\left(m_{2}+m_{3}+m_{4}\right)\left(l_{1}-a_{1}\right) \ddot{\beta}-{ }_{1}\left(m_{2} a_{2}+m_{3} l_{2}+m_{4} l_{2}\right) \ddot{\beta}-{ }_{2} \\
& -\left(m_{3} a_{3}+m_{4} l_{3}\right) \ddot{\beta}_{3}-m_{4} a_{4} \ddot{\beta}_{4}+\left(m_{2}+m_{3}+m_{4}\right)\left(l_{1}-a_{1}\right) \beta \dot{\beta}^{2}+ \\
& +(m a+m l+m l) \underset{42}{\beta} \beta_{2}^{\beta_{2}^{2}}+(m a+m l) \underset{33}{\beta} \beta_{3}^{2}+m a \beta_{344} \beta^{2}- \\
& -\left(F_{k 1}^{\prime}-F_{r f 1}^{\prime}-F_{r f 1}\right) \beta_{1}+\left(F_{r f 2}+R_{2}\right) \beta_{2}+F_{r f 3} \beta_{3}+\left(F_{r f 4}+R_{4}\right) \beta_{4}= \\
& =-F_{\delta 1}^{\prime}+F_{r f 1}^{\prime} \alpha-F_{\delta 2}^{\prime}-F_{\delta 2}-F_{\delta 4} \text {; } \\
& -(m+m+m)(l-a) \ddot{y}+\left\lceil I+m(l-a)^{2}+m(l-a)^{2}+m(l-a)^{2}+\right. \\
& \left.(d)^{2} \quad 2 I^{\prime}(d+d)\left\lceil(d+d)^{2}+a \alpha\right\rceil^{1}\right\rceil
\end{aligned}
$$

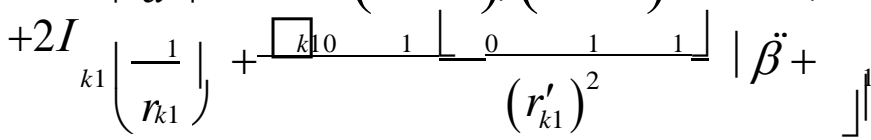

$$
\begin{aligned}
& +\left[m_{2} a_{2}+m_{3} l_{2}+m_{4} l_{2}\right]\left(l_{1}-a_{1}\right) \ddot{\beta}_{2}+\left(m_{3} a_{3}+m_{4} l_{3}\right)\left(l_{1}-a_{1}\right) \ddot{\beta}_{3}+m_{4}\left(l_{1}-a_{1}\right) a_{4} \ddot{\beta}_{4}- \\
& -\left(m_{2}+m_{3}+m_{4}\right)\left(l_{1}-a_{1}\right)^{2} \beta_{1} \dot{\beta}_{1}^{2}-\left(m a_{2} \square_{l}{ }_{2} m_{4} m_{4} l_{2}\right)(l-a) \beta \dot{\beta^{2}-} \\
& -\left(m_{3} a+m l\right)(l-a) \underset{3_{3}}{\beta} \dot{\beta}^{2}-m\left(l-a_{1}\right) a_{4} \beta_{4} \dot{\beta}^{2}+\frac{2 I_{k 1}^{\prime}\left(d_{0}+d_{1}\right) d_{0} \alpha}{\left(r_{k 1}^{\prime}\right)^{2}} \dot{\beta}_{1}^{2}- \\
& -\left(-F_{r f 2}-R_{2}-F_{r f 3}-F_{r f 4}-R_{4}\right)\left(l_{1}-a_{1}\right) \beta_{1}-\left(F_{r f 2}+R_{2}\right)\left(l_{1}-a_{1}\right) \beta_{2}-F_{r f 3}\left(l_{1}-a_{1}\right) \beta_{3}- \\
& -\left(F_{r f 4}+R_{4}\right)\left(l_{1}-a_{1}\right) \beta_{4}=M_{C 1}+\left(F_{\delta 2}+F_{\delta 4}\right)\left(l_{1}-a_{1}\right) \text {; }
\end{aligned}
$$




$$
\begin{aligned}
& -\left(m_{2} a_{2}+m_{3} l_{2}+m_{4} l_{2}\right) \ddot{y}_{1}+\left(m_{2} a_{2}+m_{3} l_{2}+m_{4} l_{2}\right)\left(l_{1}-a_{1}\right) \ddot{\beta}+{ }_{1} \\
& +I+m a^{2}+m l^{2}+m l^{2}+I_{k 2}\left(d^{2}+d^{2}\right) \ddot{\beta}+(m l a+m l l) \ddot{\beta}+ \\
& {\left[\begin{array}{llllllllllll}
2 & 2 & 2 & 32 & 42 & \overline{r_{k 2}^{2}} & l_{2} & r_{2}
\end{array}\right\rfloor \begin{array}{lllll}
2 & 32 & 3 & 423 & 3
\end{array}} \\
& +m_{4} l_{2} a_{\beta_{4}} \ddot{\beta}_{4}-\left(m_{2} a_{2}+m_{3} l_{2}+m l_{4}\right)_{2}\left(l_{1} a\right)_{1} \beta \dot{\beta}^{2}-\left(m a_{2}^{2} \frac{m}{2} l_{3}^{2}+m l_{42}^{2}\right) \beta \dot{\beta}_{2}^{2}- \\
& -\left(m_{3} l_{2} a_{3}+m_{4} l_{2} l_{3}\right) \beta_{3} \dot{\beta}_{3}^{2}-m_{4} a_{4}{ }_{2} \beta \dot{\beta}_{4}^{2}-\left(-F_{r f 3} l_{2}-F_{r f 4} l_{2}-R_{4} l_{2}\right) \beta_{2}- \\
& -F_{r f 3} l_{2} \beta_{3}-\left(F_{r f 4} l_{2}+R_{4} l_{2}\right) \beta_{4}=M_{O 2}+F_{\delta 4} l_{2} \text {; } \\
& -\left(m_{3} a_{3}+m_{4} l_{3}\right) \ddot{y}_{1}+\left(m_{3} a_{3}+-m_{4} l_{3}\right)\left(l_{1}-a_{1}\right) \ddot{\beta}+t_{1}\left(m_{3} a_{3} l_{2}+m_{4} l_{3} l_{2}\right) \ddot{\beta}++_{2} \\
& +I+m l^{2}+{ }^{k 3}\left(d^{2}+d^{2}\right) \ddot{\beta}+m l a \ddot{\beta}-(m a+m l)(l-a) \beta \dot{\beta}^{2}-
\end{aligned}
$$

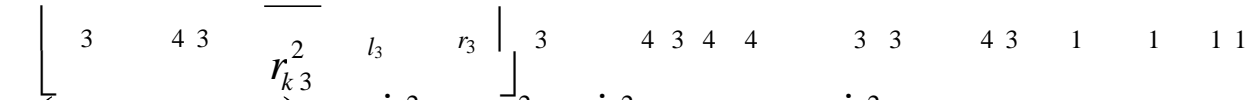

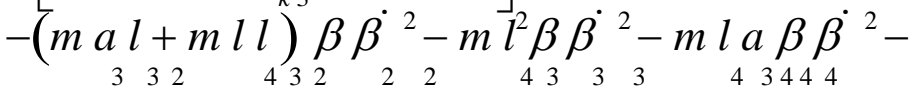

$$
\begin{aligned}
& -\left(-F_{r f 4} l_{3}-R_{4} l_{3}\right) \beta_{3}-\left(F_{r f 4} l_{3}+R_{4} l_{3}\right) \beta_{4}=M_{O 3}+F_{\delta 4} l_{3} \text {; } \\
& -m_{4} a_{4} \ddot{y}_{1}+m_{4} a_{4}\left(l_{1}-a_{1}\right) \ddot{\beta}{ }_{1}+m_{4} a_{4} l_{2} \ddot{\beta}_{2}+m_{4} a_{3} l_{3} \ddot{\beta}+ \\
& +I+m a^{2}+{ }_{k 4}\left(d^{2}+d^{2}\right) \ddot{\beta}-m a(l-a) \beta \beta^{2}- \\
& \left\lfloor\left.\begin{array}{lllll}
4 & 44 & r_{k 4}^{2} & l_{4} & r_{4}
\end{array}\right|^{4} \quad \begin{array}{llllll}
4 & 4 & 1 & 1 & 11
\end{array}\right. \\
& -m_{4} a_{4} \beta \dot{\beta}_{2}^{2}-m_{4} a_{4}{ }_{3} \beta_{3} \dot{\beta}_{3}^{2}-m_{4} a_{4}^{2} \beta \dot{\beta}^{2}=M_{O 4} \text {; }
\end{aligned}
$$

The equation (2) of this system describes the motion of an aggregate wheeled tractor along the axis $O x$; equation (3) - the motion of the aggregating tractor along the axis $\mathrm{Oy}$; equation (4) - rotation of the tractor around its center of mass; equation (5) describes the rotation of the first fertilizer unit; equation (6) couplings; equation (7) - seeding unit.

At small corners $\beta_{1}, \beta_{2}, \quad \beta_{3}, \beta_{4}$, small speeds and small products $\dot{\beta}_{1}, \dot{\beta}_{2}, \dot{\beta}_{3}, \quad \dot{\beta}$ will also be small $\beta_{1} \cdot \dot{\beta}_{1}^{2}, \quad \beta_{2} \cdot \dot{\beta}_{2}^{2}, \quad \beta_{3} \cdot \dot{\beta}_{3}^{2}, \quad \beta_{4} \cdot \dot{\beta}_{4}^{2}$. Therefore, the terms of the equations (3-7) containing the specified products, as well as the mass of the third link of the fertilizer-seed aggregate, due to their relative size can be neglected.

As a result of linearization of the received system of differential equations of a plane-parallel motion of a combined fertilizer-seeding machine-tractor unit, its calculated mathematical model took the form:

$$
\begin{aligned}
& K_{21} \cdot y_{1}(p)+K_{22} \cdot \beta_{1}(p)+K_{23} \cdot \beta_{2}(p)+K_{25} \cdot \beta_{4}(p)=K \cdot \alpha(p)+K_{1} \cdot 1(p) \text {, } \\
& K_{31} \cdot y_{1}(p)+K_{32} \cdot \beta_{1}(p)+K_{33} \cdot \beta_{2}(p)+K_{35} \cdot \beta_{4}(p)=B_{3} \cdot 1(p) \text {, } \\
& K \cdot y(p)+K \cdot \beta(p)+K \cdot \beta(p)+K \cdot \beta(p)=B \cdot 1(p) \text {, } \\
& K_{61} \cdot y_{1}(p)+K_{62}^{42} \cdot \beta_{1}(p)+K_{63} \cdot \beta_{2}(p)+K_{65} \cdot \beta_{4}(p)=B_{6} \cdot 1(p),
\end{aligned}
$$

where $p=\frac{d}{d t}$ - operator of a complex variable;

$K_{i}$ - coefficients reflecting the structural-technological and other parameters of each and the second level of this dynamic system. 
The analysis of the controllability of the motion of the combined combined machine-tractor unit will be carried out according to the well-known method of the theory of automatic control of dynamic systems [8] by constructing the corresponding amplitude-frequency characteristics (AFC) and phase-frequency characteristics (FFs) when working out the fertilizer-seeding control unit, which is The angle of rotation of the front wheels of the aggregate tractor. The first ones characterize the degree of amplification by the dynamic input signal system, and the second is the magnitude of the lateness of its response to this signal.

In the process of theoretical research the following parameters of the fertilizer-seeding unit were considered: rolling resistance coefficient $f$ of the running gear system of the aggregate tractor, as well as

wheel and grain seeders; $a_{2}, a_{4}$ - distance from the points of the trailer of the carcass and grain seeders to

the centers of their mass; $l_{2}, l_{4}$ - the length of the seedlings of fat and grain seeders.

Analysis of the dynamical system showed that the delay of its reaction to the control effect is constant and equal to 180 degree or 3.14 rad. Such a course of the phase of working out the control influence is inherent in conservative dynamic systems with practically absent dissipative processes.

The analysis of the received amplitude-frequency characteristics showed that for the same frequency of oscillations of the control influence the coefficient of its amplification by the dynamic system is greater, the larger the rolling resistance coefficient $f$ (fig. 2).

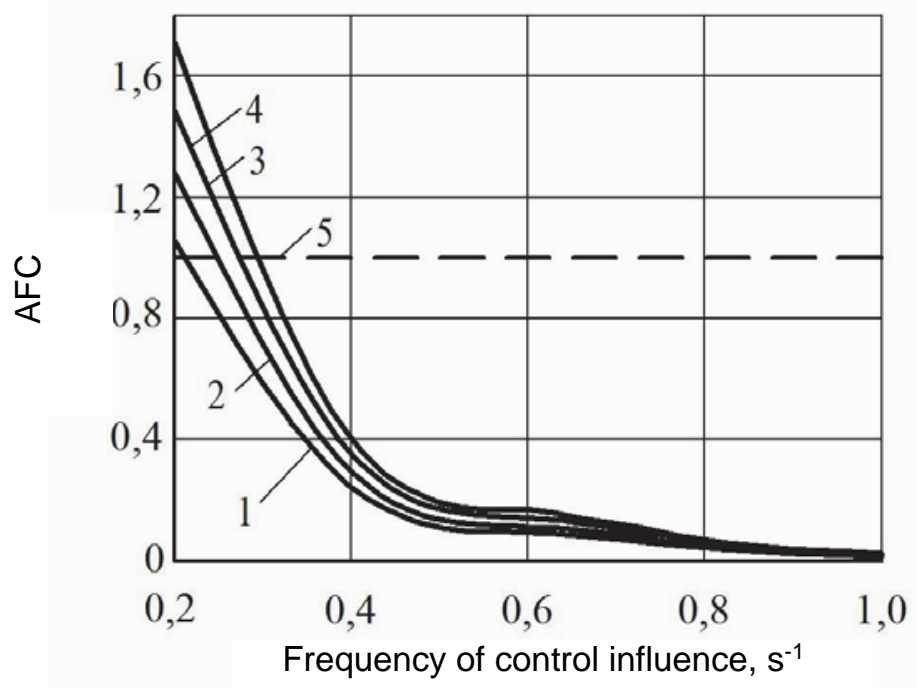

Fig. 2 - Amplitude-frequency characteristics of reproduction by a dynamic control system under different values of the rolling resistance coefficient: 1 - 0.10; 2 - 0.12; 3 - 0.14; 4 - 0.16; 5 - desired (ideal) amplitudefrequency characteristic

Analysis of the results of mathematical modeling shows that the increase of the parameter $a_{2} \quad 31,15 \mathrm{~m}$ до 3,15 м на частотах коливань керуючого впливу $\omega<0,24 \mathrm{c}$ preferably on frequencies $\omega \geq 0,3 \mathrm{c}^{\prime} \mathrm{a}$ ? undesirably reduces the actual amplitude-frequency characteristics (Fig. 3).

At the same time, depending on the agrotechnical background, the frequency of oscillation of the controlling influence should vary within the range of $0.210 \ldots 0.295 \mathrm{~s}^{-1}$, where the actual amplitude-frequency characteristic corresponds to the ideal.

The analysis of the results of mathematical modeling shows that the increase of the parameter from 1.15 $\mathrm{m}$ to $3.15 \mathrm{~m}$ at the oscillation frequencies of the control influence $\omega<0.24 \mathrm{~s}^{-1}$ is desirable, and at the frequencies $\omega \geq 0.3 \mathrm{~s}^{-1}$ it is undesirable to reduce the actual amplitudes-frequency characteristics (fig. 3). 


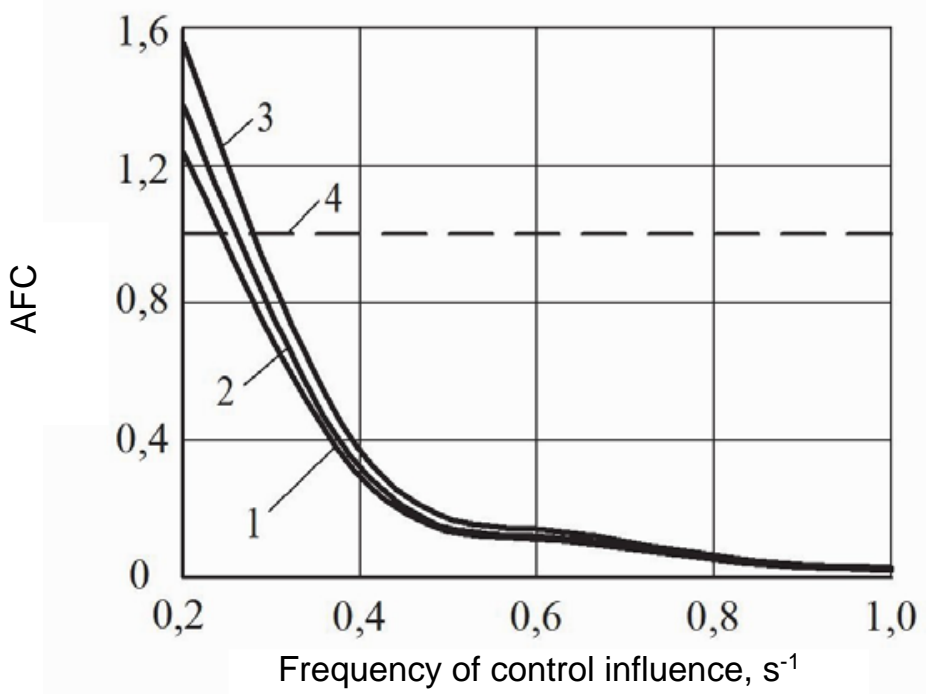

Fig. 3 - Amplitude-frequency characteristics of reproduction by a dynamic control system under different

values of the constructive parameter $a_{2}: 1-1.15 m ; 2-2.15 m ; 3-3.15 m ; 4$ - desired (ideal) amplitudefrequency characteristic

Thus, for $\omega=0.2 \mathrm{~s} a=3.15 \mathrm{~m}$, the amplitude-frequency characteristic of working out with a dynamic control system is 1.58 (curve 1, fig. 3). In reality, this means that the directional angle 1 of the aggregate tractor of this combined fertilizer-seeding machine-tractor unit (fig. 1) in relation to the steering angle of its driven wheels will vary with an increase of 1.58 times. At the same time, with a decrease of the parameter to $1.15 \mathrm{~m}$, the indicated undesired overregulation will be more than twice as small, as the amplitude-frequency characteristic of the system under study will then drop to 1.23 (curve 3, fig. 3).

For setting the frequency of oscillations of the rotation of the controlled wheels of the power tool at the level $\omega=0,3 \mathrm{~s}$, the amplitude-frequency characteristic of the cultivating fertilizer control unit $a=1.15 \mathrm{~m}$ is, in general, ideal, that is equal to 1 (curve 1, fig. 3 ) The increase of the considered design parameter to 3.15 $\mathrm{m}$ at the same frequency reduces the amplitude-frequency characteristic to a value of 0.7 (curve 3 , fig. 3 ). In this case, the dynamic system reproduces a controlling influence with a $30 \%$ underexposed, which is an undesirable fact.

And only in the frequency range of the oscillation of the steering angle of the tractor wheels from $0.24 \mathrm{~s}^{-1}$ to $0.30 \mathrm{~s}^{-1}$ (fig. 3), it is possible to select such a value of a constructive parameter that will facilitate practically the perfect handling of the movement of this combined fertilizer- Sowing machinery and tractor unit.

A qualitatively similar conclusion can be made regarding the choice of a constructive parameter. The abrogation of this is that the frequency range of oscillations of the control influence, in which the actual amplitude-frequency characteristics of the considered dynamic system (that is, the considered combined machine-tractor unit) correspond to the ideal, are somewhat narrower $0.23 \ldots 0.26 \mathrm{~s}-1$.

If the increase in the design parameter determines the unambiguous behavior of the corresponding

amplitude-frequency characteristics of the dynamic system, then the same change in the parameter $l_{2}$ no. Thus, for frequency $\omega=0.2 \mathrm{~s}^{-1}$, for example, the amplitude-frequency characteristic $f()$ is non-correlated and almost linear (curve 1, fig. 4). 


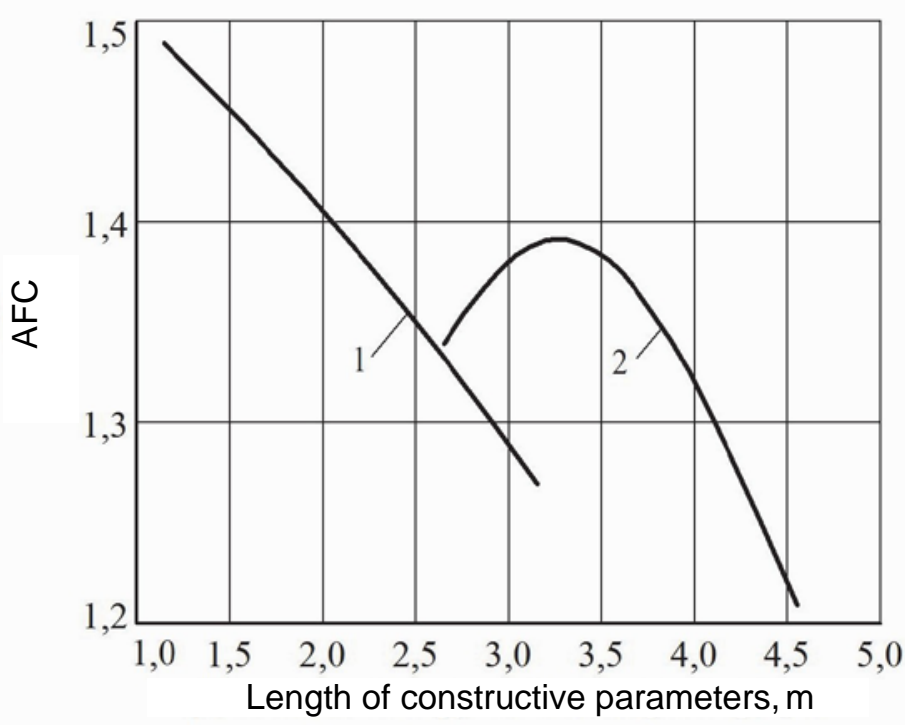

Fig. 4 - Amplitude-frequency reproduction characteristics dynamic system of controlling influence of frequency $0,2 s^{-1}$ for different values of constructive parameters $a_{2}(1)$ and $l_{2}(2)$

At the same time, the function $f\left(l_{2}\right)$ of the amplitude-frequency characteristic at the frequency $\omega=0.2 \mathrm{~s}^{-1}$ is curvilinear and to some extent close to the parabolic (curve 2, fig. 4). And this type of dependence of the amplitude-frequency characteristic on the parameter $l_{2}$ is maintained with increasing frequency of oscillations of the angle of rotation of the driven wheels of the tractor.

The character of the change of curve 2 (fig. 4) indicates that when selecting a parameter $l_{2}$, the advantage should be given to its greater value. In this case, the value of the actual amplitude-frequency characteristic of the dynamic system is closer to 1.

At the same time, an increase in the parameter $l_{2} \quad$ causes the grain seeder 4 to rotate relative to the fodder seeder 2 (fig. 1) without colliding with the combined fertilizer-seeding machine-tractor unit on the turntable. As a result, this means that the threshold for increasing the parameter is its value, which will determine the accidental rotation of the combined aggregate.

The analysis of the results of modeling the controlled motion of a combined fertilizer-sowing unit in a

horizontal plane shows that the influence on this process of the structural parameters $a_{4}$ and $l_{4}$ (fig. 1), as well as the parameters and qualitatively and quantitatively is similar.

\section{Conclusions}

1. From the standpoint of stable motion, a mathematical model of its functioning in a longitudinalhorizontal plane can be used to substantiate structural and kinematic parameters.

2. Depending on the surface of the cultivated field, working out the dynamic system of the combined fertilizer-seeding unit of the vibration of the angle of rotation of the controlled wheels of the aggregate tractor is desirable without amplification in the frequency range $0,210 \ldots 0,295 \mathrm{~s}^{-1}$. At the same time, its larger values are characteristic of the unit's operation on a more loose agrotechnical background, and smaller ones on a more solid one.

3. At the frequency of oscillation of the angle of rotation of the driven wheels of the aggregate tractor smaller than $0.24 \mathrm{~s}^{-1}$, it is desirable to increase the distance from the points of the trailer of the fat and grain seeders to the centers of their masses from $1.15 \mathrm{~m}$ to $3.15 \mathrm{~m}$, and at frequencies greater than $0.3 \mathrm{~s}^{-1}$ - it is undesirable, since the dynamic system reproduces the controlling influence with underexploitation. 
4. A qualitatively similar conclusion can be made also regarding the choice of the length of the sowing of fat and grain seeders. The abolition of this is that the desired frequency range for the rotational angles of the steering wheels of the aggregate tractor is slightly more narrow $0.23 \ldots 0.26 \mathrm{~s}^{-1}$. At the same time, the limit of increasing the length of the sowing of the fodder seeder is its value, which will determine the accidental rotation of the combined aggregate.

\section{References}

1. Prysyazhnyuk M.V. Osoblyvosti provedennya vesnyano-pol'ovykh robit v zoni stepu v 2012 rotsi / M.V. Prysyazhnyuk [ta in.]. — Dnipropetrovs'k: DU IS·HSZ NAAN Ukrayiny, 2012. - $111 \mathrm{~s}$.

2. Lykhochvor V. Systema udobrennya ozymoyi pshenytsi / V. Lykhochvor // Ahrobiznes s'ohodni. 2014. — №7(278). — S. 24-57.

3. Perspektivy ispol'zovaniya kombinirovannykh mashinno-traktornykh agregatov / V. Kyurchev [i dr.] // Nauchni izvestiya. — Varna (Bolgariya), 2013. - T. XXI, Vyp. 5 (142). - S. 104-108.

4. Geruk S.N. Analiz konstruktsiy agregatov dlya predposevnoy obrabotki pochvy i poseva / Geruk S.N., Petrichenko Ye.A. Materialy Mezhdunarodnoy nauchno-tekhnicheskoy konferentsii "Nauchno-tekhnicheskiy progress v sel'skokhozyaystvennom proizvodstve", (Minsk, 22-23 oktyabrya 2014 g.), Tom 2. — Minsk, NPTS NAN Belarusi po mekhanizatsii sel'skogo khozyaystva, 2014. - S. 147-152.

5. Wong J.Y. Theory of ground vehicles / J.Y. Wong. — 3rd ed. — John Wiley \& Sons, Inc., 2001. — 558 p.

6. Dubrovin $V$. Maszyny z regulowana jakoscia wykonywania procesow technologicznych w produkcji roslinnej / V. Dubrovin, V. Myronenko // Materialach XI Miedzynarodowe Symposjum "Ekologiczne aspekty mechanizacji produkcji roslinnej"; Warszawa, 2005. - C. 206-209.

7. Vasilenko P.M. Elementy teorii ustoychivosti dvizheniya pritsepnykh sel'skokhozyaystvennykh mashin $\mathrm{i}$ orudiy / P.M. Vasilenko // Sbornik trudov po zemledel'cheskoy mekhanike. -1954. — Tom Íl. — S. 202-211.

8. Solodovnikov V.V. Osnovy teorii i elementov sistem avtomaticheskogo regulirovaniya. Uchebnoye posobiye dlya vuzov / V.V. Solodovnikov, V.N. Plotnikov, A.V. Yakovlev. - M.: Mashinostroyeniye, 1985. $536 \mathrm{~s}$. 